\title{
Implementasi Sistem Pakar Untuk Mendeteksi Gejala Defisiensi Vitamin Pada Tubuh Manusia Pada Puskesmas
}

\author{
Ranti Eka Putri*a , Rika Widyab \\ Universitas Pembangunan Pancabudi, Fakultas Sistem Komputer a \\ Universitas Pembangunan Pancabudi, Fakultas Agama Islam dan Humaniora b \\ rantiekaputri@dosen.pancabudi.ac.id
}

\begin{abstract}
Abstrak
Penelitian ini membahas mengenai Sistem Pakar dengan metode Backward Chaining. Rancangan aplikasi dari Sistem Pakar itu sendiri dirancang dengan berbasis web, karena dengan aplikasi berbasis web dapat membantu proses penyebaran informasi dan pengetahuan dengan daerah penyebaran yang lebih luas. Vitamin merupakan nutrien organic yang dibutuhkan dalam jumlah kecil untuk berbagai fungsi biokimiawi dan yang umumnya tidak disintesis oleh tubuh. Vitamin mempunyai berbagai fungsi yang essensial dalam proses metabolisme tubuh yang normal. Kekurangan atau defisiensi terhadap vitamin dapat menjadi masalah bagi kesehatan manusia sehingga menimbulkan berbagai penyakit pada tubuh. Untuk membantu orang-orang dalam mengetahui gejala-gejala defisiensi tiap-tiap vitamin pada tubuh yang dapat dilihat dan dirasakannya tanpa harus melakukan konsultasi ke ahli gizi atau dokter, maka perlulah di implementasikan sebuah sistem pakar untuk diagnosa defisiensi vitamin.
\end{abstract}

Keywords: Sistem Pakar, Defisiensi, Vitamin, Backward Chaining, Web

\section{Pendahuluan}

Puskesmas adalah unit pelaksana teknis Dinas Kesehatan kabupaten/Kota yang bertanggung jawab dalam menyelenggarakan pembangunan kesehatan di suatu wilayah kerja. Mereka harus memberikan pelayanan preventif, promotif, kuratif sampai dengan rehabilitatif baik melalui upaya kesehatan perorangan (UKP) atau upaya kesehatan masyarakat (UKM).

Saat ini perkembangan teknologi informasi dari hari ke hari semakin berkembang dan pemanfaatan teknologi pun telah merambah ke berbagai aspek kehidupan, salah satunya adalah pada aspek kesehatan. Untuk mengoptimalkan layanan pada puskesmas, diperlukannya pemanfaatan teknologi yang dapat memudahkan masyarakat sekitar, salah satunya mengimplementasikan sebuah sistem pakar. Peneliti tertarik melakukan penelitian mengenai sistem pakar untuk diagnosa defisiensi vitamin. Karena dengan adanya sistem pakar ini pada puskesmas, dan puskesmas mensosialisasikannya kepada masyarakat. Masyarakat akan memiliki alternatif lain untuk mendapatkan atau mengetahui mengenai gejala-gejala defisiensi pada tiap-tiap vitamin. Penelitian ini membahas mengenai Sistem Pakar dengan metode Backward Chaining. Rancangan aplikasi dari Sistem Pakar itu sendiri dirancang dengan berbasis web, karena dengan aplikasi berbasis web dapat membantu proses penyebaran informasi dan pengetahuan dengan daerah penyebaran yang lebih luas.

Vitamin merupakan nutrien organic yang dibutuhkan dalam jumlah kecil untuk berbagai fungsi biokimiawi dan yang umumnya tidak disintesis oleh tubuh. (Rusdiana et al., 2004) Vitamin mempunyai berbagai fungsi yang essensial dalam proses metabolisme tubuh yang normal. Kekurangan atau defisiensi terhadap 
vitamin dapat menjadi masalah bagi kesehatan manusia sehingga menimbulkan berbagai penyakit pada tubuh. Untuk membantu orang-orang dalam mengetahui gejala-gejala defisiensi tiap-tiap vitamin pada tubuh yang dapat dilihat dan dirasakannya tanpa harus melakukan konsultasi ke ahli gizi atau dokter, maka perlulah di implementasikan sebuah sistem pakar untuk diagnosa defisiensi vitamin.

Sistem pakar secara umum adalah sistem yang berusaha mengadopsi pengetahuan manusia ke komputer, agar komputer dapat menyelesaikan masalah seperti yang biasa dilakukan oleh para ahli. (Destarianto et al., 2013)

Expert System (ES), Knowledge-Based Expert System, Knowledge-Based System (KBS) atau Sistem Pakar adalah sebuah program berbasis pengetahuan yang menyediakan penyelesaian 'berkualitas pakar' untuk masalah-masalah dalam sebuah bidang yang spesifik. (Saputra et al., 2012)

Basis pengetahuan Knowledge-Based mengandung pengetahuan untuk pemahaman, formulasi, dan penyelesaian masalah. Komponen sistempakar ini disusun atas dua elemen dasar, yaitu fakta dan aturan. Fakta merupakan informasi tentang obyek dalam area permasalahan tertentu, sedangkan aturan merupakan informasi tentang cara bagaimana memperoleh fakta baru dari fakta yang telah diketahui. (Yanti, n.d.)

Knowledge merupakan kunci utama dari sistem pakar. Analoginya dengan ekspresi klasik dari Wirth adalah (Saputra et al., 2012) : Algoritma + Struktur Data $=$ Program Dan untuk sistem pakar: Knowledge + Inferensi $=$ Sistem pakar

Runut balik (Backward Chaining) merupakan strategi pencarian yang arahnya kebalikan dari runut maju (Forward Chaning). Proses pencarian dimulai dari tujuan, yaitu kesimpulan yang menjadi solusi permasalahan yang dihadapi (Tarigan, 2014)

\section{Metode}

Penelitian ini merupakan jenis penelitian kualitatif dengan melakukan akuisisi pengetahuannya langsung dari narasumber (pakar). Pakar disini merupakan orang yang ahli dalam suatu bidang tertentu dan telah memiliki pengetahuan dan pengalamannya untuk mengambil keputusan lebih tepat. Pakar Sistem Pakar untuk diagnosa defisiensi vitamin pada tubuh ini adalah ahli / dokter gizi. Pengetahuan dari pakar ini digunakan untuk memberikan informasi tentang permasalahan yang menjadi bahan acuan dalam mendesain Sistem Pakar. Setelah dilakukannya akuisisi pengetahuan baru langkah selanjutnya yang dilakukan peneliti yaitu representasi pengetahuan.

\section{Hasil dan Pembahasan}

Setelah proses pengumpulan data selesai dilakukan, maka dilakukan representasi data ke dalam basis pengetahuan dan basis aturan yang kemudian dikodekan, diorganisasikan dan digambarkan dalam bentuk pohon keputusan sehingga menjadi bentuk yang sistematis. Adapun representasi pengetahuan yang dilakukan ke dalam Sistem Pakar diagnosa defisiensi vitamin ini adalah dengan menggunakan tabel keputusan defisiensi vitamin, dimana tabel tersebut berisikan 
Community Engagement \& Emergence Journal

Vol. 1 No. 12020 , pp: 8-13

hubungan antara gejala dengan jenis defisiensi vitamin. Tabel 1 merupakan tabel keputusan defisiensi vitamin.

Tabel 1. Tabel Keputusan

\begin{tabular}{|c|c|c|c|c|c|c|c|c|c|c|c|c|c|}
\hline 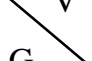 & VT01 & VT02 & VT03 & VT04 & VT05 & VT06 & VT07 & VT08 & VT09 & VT10 & VT11 & VT12 & VT13 \\
\hline GJ01 & $\sqrt{ }$ & & & & & & & & & & & & \\
\hline GJ02 & $\sqrt{ }$ & & & $\sqrt{ }$ & $\sqrt{ }$ & & & & $\sqrt{ }$ & & & & \\
\hline GJ03 & $\sqrt{ }$ & & & & & & & & & $\sqrt{ }$ & & & \\
\hline GJ04 & $\sqrt{ }$ & & & & & & & & & & & & \\
\hline GJ05 & $\sqrt{ }$ & & & & & & & $\sqrt{ }$ & & & & & \\
\hline GJ06 & $\sqrt{ }$ & & & & & & & & & & & & \\
\hline GJ07 & $\sqrt{ }$ & & & & & & & & & & & $\sqrt{ }$ & \\
\hline GJ08 & & $\sqrt{ }$ & & & & & $\sqrt{ }$ & & & & & & \\
\hline GJ09 & & $\sqrt{ }$ & & & & & & & & & & & \\
\hline GJ10 & & $\sqrt{ }$ & & $\sqrt{ }$ & & & & & & & & & \\
\hline GJ11 & & $\sqrt{ }$ & & $\sqrt{ }$ & & $\sqrt{ }$ & & $\sqrt{ }$ & $\sqrt{ }$ & & & & \\
\hline GJ12 & & $\sqrt{ }$ & & & & & & & & & & & \\
\hline GJ13 & & $\sqrt{ }$ & & & & & & & $\sqrt{ }$ & & & & \\
\hline GJ14 & & & $\sqrt{ }$ & & & & & & & & & & \\
\hline GJ15 & & & $\sqrt{ }$ & & & & & & & & & & \\
\hline GJ16 & & & $\sqrt{ }$ & & & & & & & & & & \\
\hline GJ17 & & & $\sqrt{ }$ & & & & & & & & & & \\
\hline GJ18 & & & & $\sqrt{ }$ & & & & & & & & & \\
\hline GJ19 & & & & $\sqrt{ }$ & & $\sqrt{ }$ & & & & & & & \\
\hline GJ20 & & & & $\sqrt{ }$ & & & & & & & & & \\
\hline GJ21 & & & & $\sqrt{ }$ & & & & & & & & & \\
\hline GJ22 & & & & $\sqrt{ }$ & & $\sqrt{ }$ & $\sqrt{ }$ & & & & & & \\
\hline GJ23 & & & & $\sqrt{ }$ & & & & & & & & & \\
\hline
\end{tabular}

Tabel 1. Tabel Keputusan Lanjutan

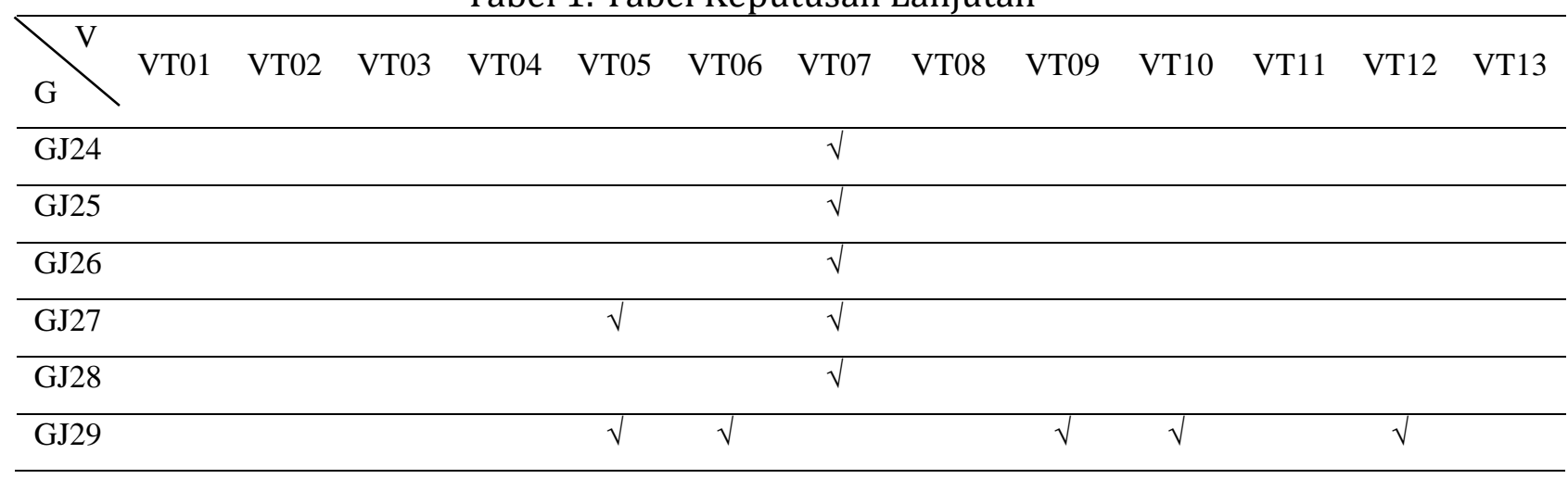


Community Engagement \& Emergence Journal

Vol. 1 No. 12020 , pp: 8-13

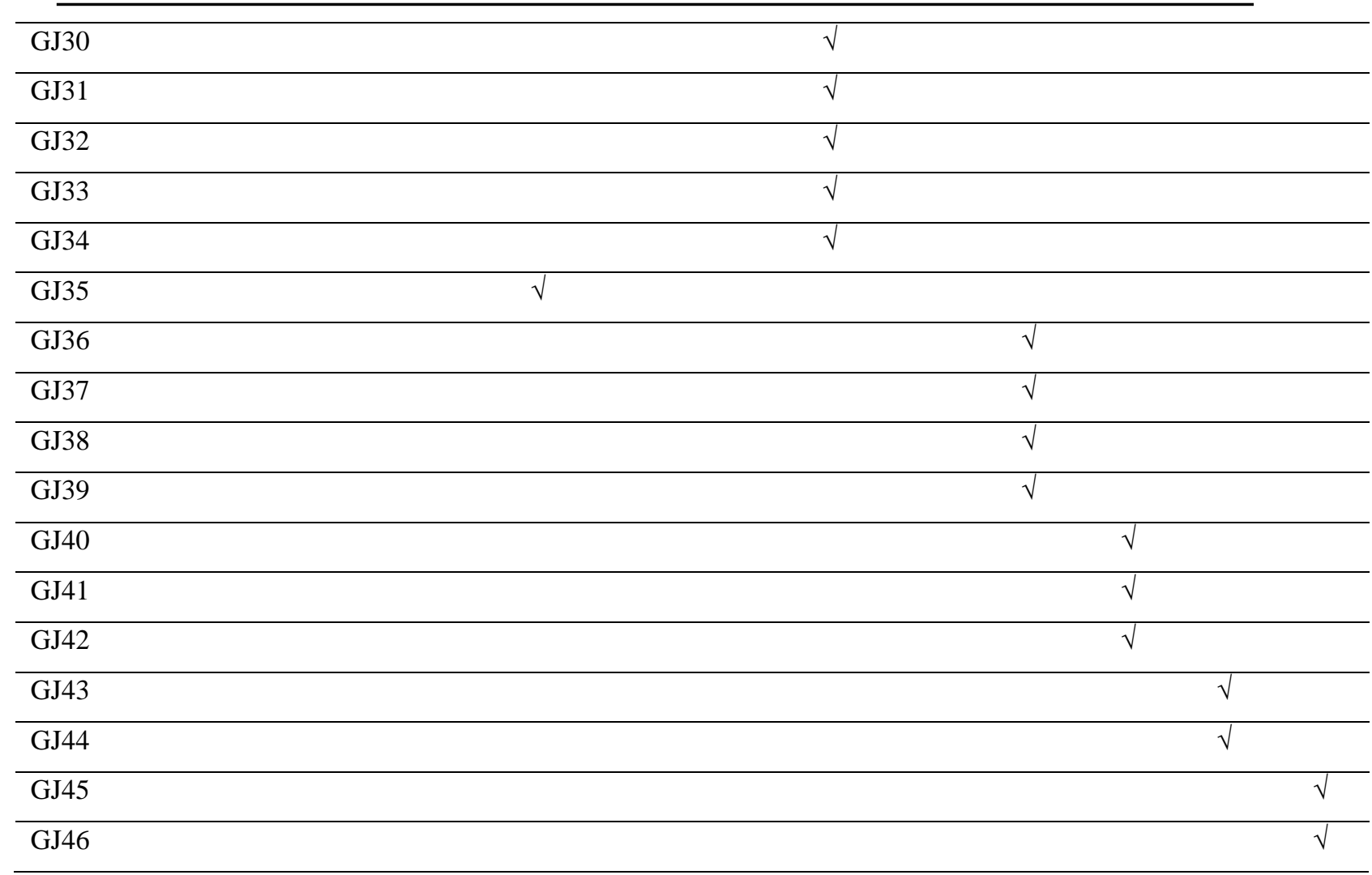

Untuk mendukung penalaran, data yang telah dipresentasikan ke dalam tabel keputusan juga di presentasikan juga ke dalam bentuk pohon keputusan. Dengan pohon keputusan, penulis dapat dengan mudah melihat serta mengidentifikasi hubungan antara vitamin dan gejala defisisensinya. Dari gejala defisiensi vitamin inilah kita akan dapat mengelompokkan gelaja -gejala dengan defisiensi tiap-tiap vitamin yang sebagaimana terlihat pada gambar 1 sebagai berikut: 


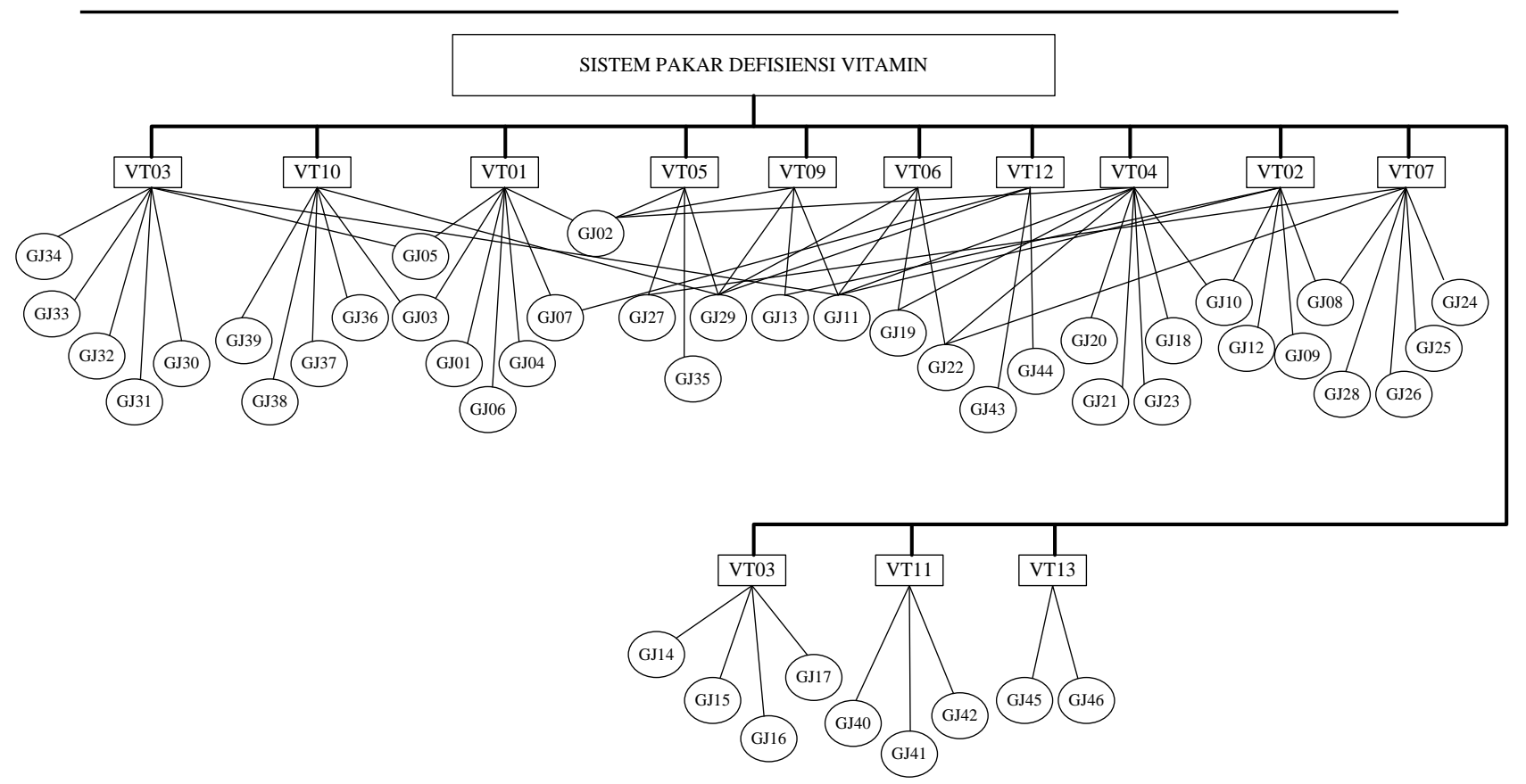

Gambar 1. Pohon Keputusan

Inferensi Backward Chaining merupakan metode yang pendekatannya adalah goal-driven, maka Sistem Pakar ini nantinya akan diuji dengan data sample dari 3 Pengguna, yaitu sebagai berikut:

1. Pengguna P1

Kasus untuk mendiagnosa defisiensi Vitamin B3 (VT04), asumsi dari rule 1 (R4):

IF GJ02 is True, AND GJ10 is True, AND GJ11 is True, AND GJ18 is True, $A N D$ GJ19 is True, AND GJ20 is True, AND GJ21 is True, AND GJ22 is True, AND GJ23 is True THEN VT04

Apabila user memilih defisiensi Vitamin B3 yaitu VT04, maka sistem akan menampilkan gejala-gejala apa saja yang dialami oleh penderita defisiensi vitamin B3.

2. Pengguna $\mathrm{P} 2$

Kasus untuk mendiagnosa defisiensi Vitamin A (VT01), asumsi dari rule 1 (R1):

IF GJ01 is True, AND GJ02 is True, AND GJ03 is True, AND GJ04 is True, AND GJ05 is True, AND GJ06 is True, AND GJ07 is True THEN VT01

Apabila user memilih defisiensi Vitamin A yaitu VT01, maka sistem akan menampilkan gejala-gejala apa saja yang dialami oleh penderita Sindrom defisiensi Vitamin A 
3. Pengguna $\mathrm{P} 3$

Kasus untuk mendiagnosa defisiensi Vitamin Biotin (VT08), asumsi dari rule 8 (R8):

IF GJ05 is True, AND GJ11 is True, AND GJ30 is True, AND GJ31 is True, AND GJ32 is True, AND GJ33 is True, AND GJ34 is True THEN VT08

Apabila user memilih defisiensi Vitamin Biotin yaitu VT08, maka sistem akan menampilkan gejala-gejala apa saja yang dialami oleh penderita defisiensi Vitamin Biotin.

\section{Simpulan}

Dengan adanya fasilitas sistem pakar untuk diagnosa defisiensi vitamin ini pada puskesmas dan pihak puskesmas mensosialisasikannya kepada masyarakat sekitar. Masyarakat dapat menggunakan sistem pakar ini untuk mengetahui gejalagejala dari defisiensi tiap -tiap vitamin tanpa harus konsultasi terlebih dahulu dengan seorang ahli gizi tanpa dibatasi ruang dan waktu karena sistem pakar ini berbasis Web.

\section{Ucapan Terimakasih}

Terima kasih kepada Lembaga Penelitian dan Pengabdian Universitas Pembangunan Panca Budi yang telah memberikan dukungan dan pendanaan skema pengabdian kepada masyarakat.

\section{Daftar Pustaka}

Destarianto, P., Yudaningtyas, E., \& Pramono, S. H. (2013). Penerapan Metode Inference Tree dan Forward Chaining dalam Sistem Pakar Diagnosis Hama dan Penyakit Kedelai Edamame Berdasarkan. 7(1), 21-27.

Rusdiana, V., Studi, P., Fakultas, B., Universitas, K., Utara, S., \& Vitamin, I. P. (2004). Digitized by USU digital library 1. 6, 1-11.

Saputra, E., Julievi, N., Islam, U., Sultan, N., Kasim, S., \& Farmasi, I. (2012). Sistem Pakar Dalam Bidang Farmakolgi dan Terapi Menggunakan Metode Pelacakan Forward Chaining. 10(1), 106-114.

Tarigan, F. A. (2014). Sistem Pakar Untuk Mendiagnosa Penyakit Ginjal dengan Metode Backward Chaining. III(2), 25-29.

Yanti, E. F. (n.d.). Penerapan Metode Forward Dan Backward Chaining Dalam Sistem Pakar Pemilihan Resep. 1-13. 